\title{
1069 Energy loss computation in the pulmonary arteries of repaired tetralogy of fallot subjects utilizing cardiac phase contrast MRI William Gottliebson*1, Ashish Das ${ }^{2}$ and Rupak K Banerjee ${ }^{2}$
}

\author{
Address: ${ }^{1}$ Cincinnati Childrens Hospital and Medical Center, Cincinnati, OH, USA and ${ }^{2}$ University of Cincinnati, Cincinnati, OH, USA \\ * Corresponding author
}

from I th Annual SCMR Scientific Sessions

Los Angeles, CA, USA. I-3 February 2008

Published: 22 October 2008

Journal of Cardiovascular Magnetic Resonance 2008, I0(Suppl I):AI94 doi:10.1 186/I532-429X-10-SI-AI94

This abstract is available from: http://jcmr-online.com/content/I0/SI/AI94

(C) 2008 Gottliebson et al; licensee BioMed Central Ltd.

\section{Introduction}

The cardiac MRI (CMR) pulmonary artery (PA) velocityarea relation (VAR) and pressure-flow relation (PFR) have been shown to change significantly in certain diseases of the PAs in which pulmonary valve function is normal. We hypothesized that the area within the PA VAR changed in concert with stroke work (an index of energy loss, represented by the integrated area of the PFR) in subjects with repaired Tetralogy of Fallot (rTOF) with residual pulmonary valve insufficiency (PI).

\section{Methods}

Concurrent catheterization (cath) and CMR data were analyzed for patients with rTOF and severe PI, and in control subjects without PI having normal as well as enlarged PAs due to a large left to right shunt. Cath data from the PAs was synchronized by ECG with concurrent MRI PA phase contrast flow (normalized to body surface area), PA cross-sectional area and PA pressure data. PA VAR and PFR curves were plotted for all subjects and the integrated areas within the curves were tabulated.

\section{Results}

In subjects with rTOF and severe PI, integrated area of VAR (0.9-1.05 cm3/s) and PFR $\left(0.3-1.0 \mathrm{mmHg}^{*} \mathrm{~cm} / \mathrm{s}\right)$ were similar and 2-3 fold greater than for the control subjects (VAR $0.1-0.4 \mathrm{~cm} 3 / \mathrm{s}$; PFR 0.09-0.1 mmHg* ${ }^{*} \mathrm{~cm} / \mathrm{s}$ ), signifying hysteresis and energy loss per stroke (representative examples in figures 1 and 2). Further, the negative velocity or flow in relation to pressure and area signifies regurgitant flow and inefficiency per stroke.

\section{Conclusion}

The CMR PA VAR curve characteristics mimic the changes in stroke work in subjects with rTOF and severe PI, and may be a reasonable non-invasive surrogate for assessment of PA thermodynamic and hemodynamic properties in this population. 


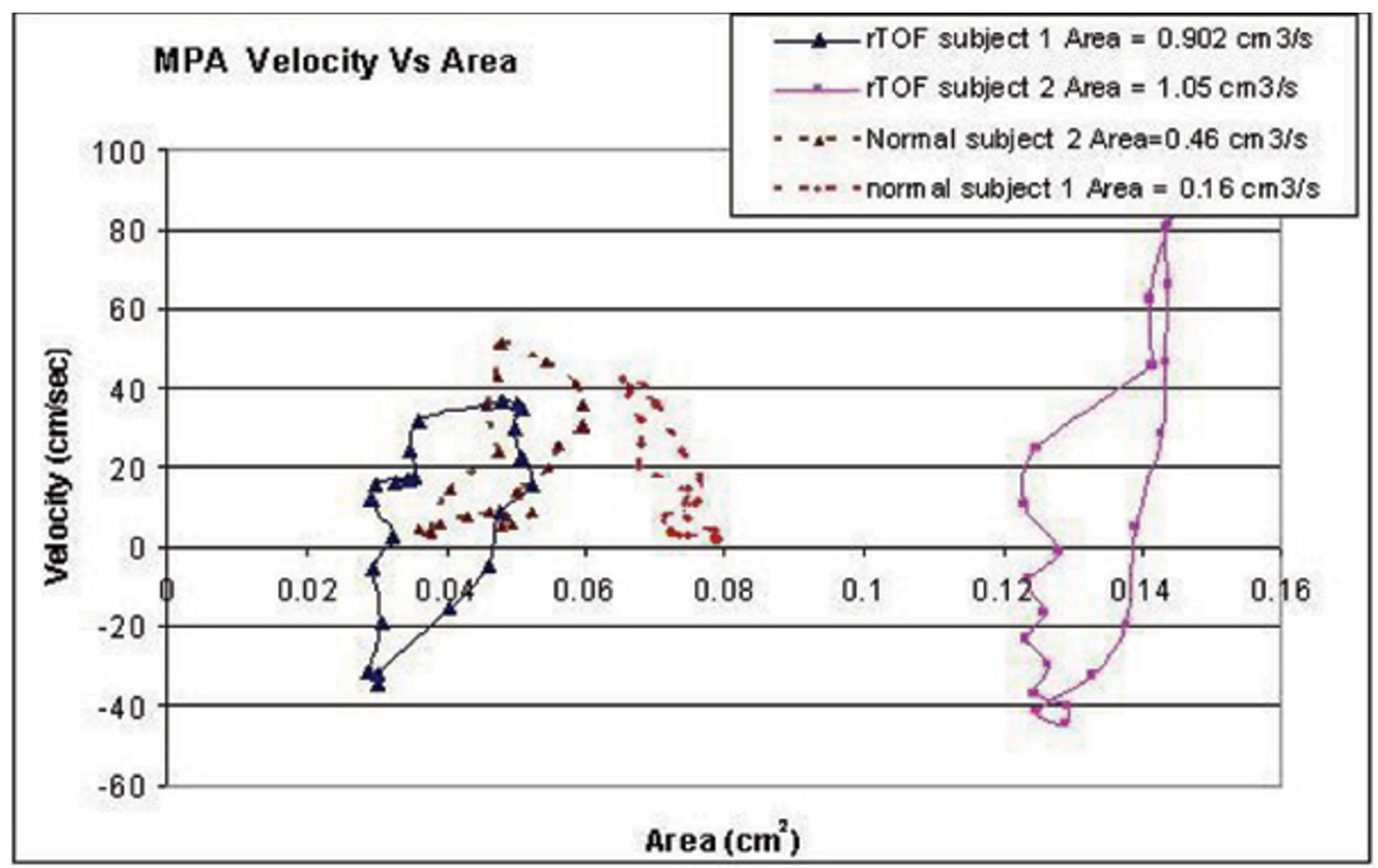

Figure I

MPA velocity Vs area. In subjects with repaired Tetralogy of Fallot and residual pulmonary valve insufficiency, the MRI-dervived pulmonary artery velocity-area relation can be used to assess energy losses in the pulmonary arteries. 


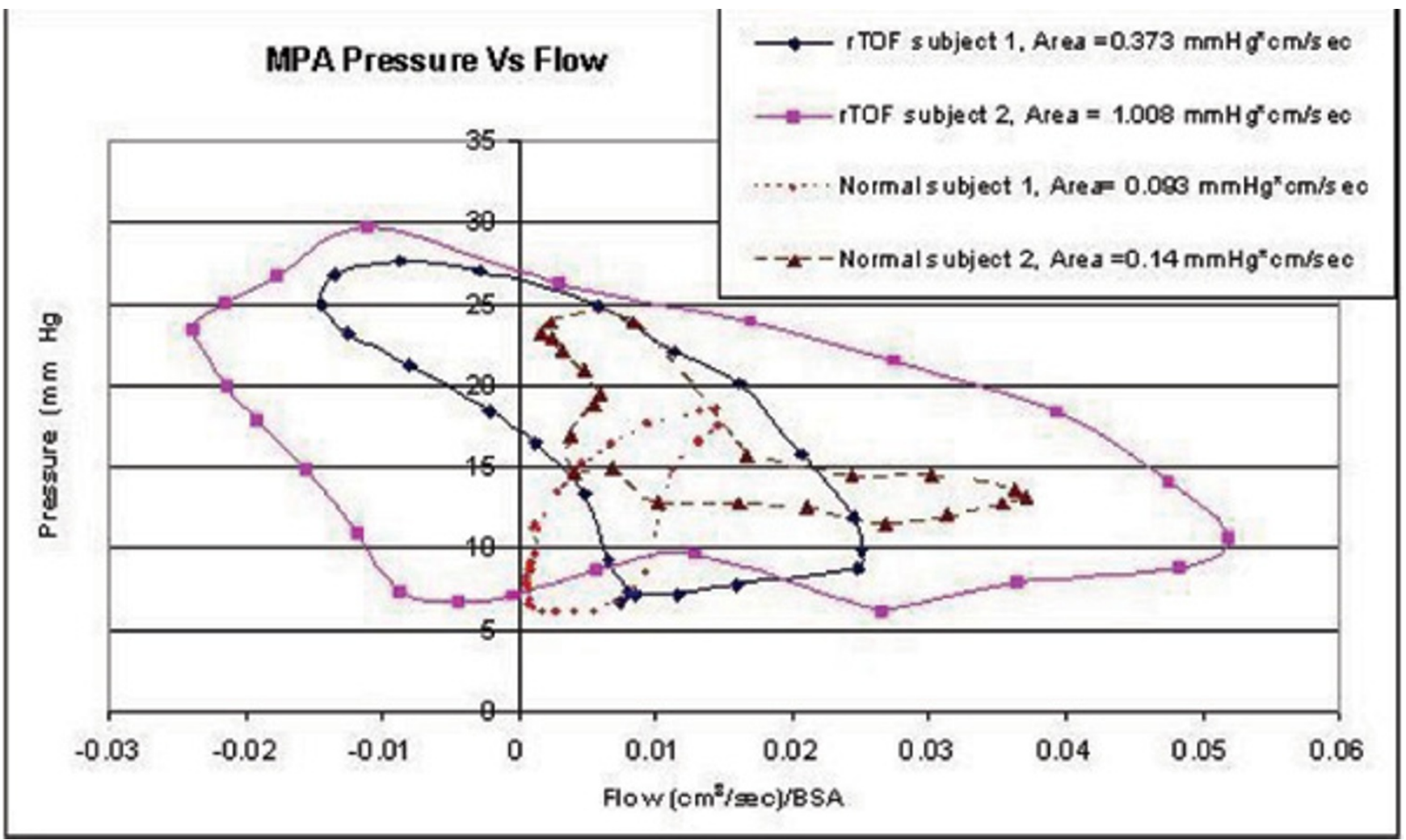

Figure 2

MPA pressure Vs flow.

Publish with Bio Med Central and every scientist can read your work free of charge

"BioMed Central will be the most significant development for disseminating the results of biomedical research in our lifetime. " Sir Paul Nurse, Cancer Research UK

Your research papers will be:

- available free of charge to the entire biomedical community

- peer reviewed and published immediately upon acceptance

- cited in PubMed and archived on PubMed Central

- yours - you keep the copyright 